\title{
Artificial turf: chemical flux and development of silicone wristband partitioning coefficients
}

\author{
Carey E. Donald ${ }^{1,2} \cdot$ Richard P. Scott $^{1} \cdot$ Glenn Wilson $^{1} \cdot$ Peter D. Hoffman ${ }^{1} \cdot$ Kim A. Anderson ${ }^{1}$
}

Received: 8 October 2018 / Accepted: 21 February 2019 / Published online: 7 March 2019

(C) The Author(s) 2019

\begin{abstract}
This work uses passive samplers to identify PAHs and OPAHs not previously associated with artificial turf, and to provide the first quantitative measure of in situ flux of semi-volatile contaminants on artificial turf fields. Both air (1.5-m height) and turf air (immediately above turf surface) were sampled using two sampling materials: low-density polyethylene and silicone. Utilizing a broad targeted screen, we assess both artificial turf and samples of crumb rubber for over 1530 chemicals including pesticides, phthalates, and personal care products. We report the presence of 25 chemicals that have not yet been reported in artificial turf literature, including some with known human effects. The samplers were also quantitatively analyzed for polycyclic aromatic hydrocarbons yielding gas-phase concentrations at breathing height and surface level - the first such report on an artificial turf outdoor field. Turf pore-air and air chemicals were highly correlated at all sites, and particularly at the recently installed indoor site. Flux of chemicals between air and turf surface appear to follow field age although more research is needed to confirm this trend. The thermal extraction process and silicone passive samplers used are suitable for larger-scale environmental sampling campaigns that aim for less solvent and sample processing. By co-deploying silicone passive samplers and conventional lowdensity polyethylene, partitioning coefficients are derived that can be used for future silicone passive air sampling environmental assessment. This study provides an initial demonstration that passive samplers can be used to quantify volatile and semi-volatile organic chemicals from artificial turf.
\end{abstract}

Keywords Polycyclic aromatic hydrocarbons - Oxygenated polycyclic aromatic hydrocarbons $\cdot$ Semi-volatile organic contaminants $\cdot$ LDPE $\cdot$ Silicone $\cdot$ Flux $\cdot$ Artificial grass $\cdot$ Synthetic turf

\section{Introduction}

Professional and amateur athletes commonly compete and practice on artificial turf. The latest generation of artificial turf is composed of several layers to mimic the look and feel of grass, often including plastic "grass" fibers and infill made of crumb rubber and/or sand (Cheng et al. 2014). Crumb rubber

Electronic supplementary material The online version of this article (https://doi.org/10.1007/s11869-019-00680-1) contains supplementary material, which is available to authorized users.

Kim A. Anderson

kim.anderson@oregonstate.edu

1 Food Safety and Environmental Stewardship Program, Department of Environmental and Molecular Toxicology, Oregon State University, 1007c Agricultural and Life Sciences Building, Corvallis, OR 97330, USA

2 Present address: Institute of Marine Research, Nordnesgaten 50, 5005 Bergen, Norway is made using recycled tires and is $\sim 90 \%$ of field material by weight (Cheng et al. 2014; Schiliro et al. 2013). Components of the recycled tires have been considered as potential toxicants, including lead, zinc, particulate matter, and volatile and semi-volatile organic chemicals (European Chemicals Agency 2017; USEPA 2016). Potential exposure routes from crumb rubber include inhalation of particles or gas-phase contaminants, dermal contact, and inadvertent ingestion of crumb rubber. Risk estimates to date have yielded mixed results, concluding either that (a) artificial turf components meet or do not exceed levels that would contribute to health risks, or (b) that some exposures are above levels that may contribute to risk (USEPA 2016 and references therein). Refining these conclusions is the subject of recent and ongoing investigations by the USEPA (2016) and the European Chemicals Agency (2017).

Semi-volatile organic chemicals, e.g., phthalates, benzothiazole, and polycyclic aromatic hydrocarbons (PAHs), are used in tire production and are commonly detected in crumb rubber analyses (Celeiro et al. 2014; Cheng et al. 
2014; Dye et al. 2006; Llompart et al. 2013; Schiliro et al. 2013). Other toxicologically relevant chemicals are also present, but crumb rubber has not yet been fully characterized, and these unknown components remain as uncertainties in risk evaluations (European Chemicals Agency 2017). Oxygenated PAHs (OPAHs), like PAHs, derive from numerous natural and anthropogenic sources. OPAHs are also formed as photo-oxidation products of PAHs (Lundstedt et al. 2007), and formation of OPAHs is likely in the highsun environment typical on outdoor sports fields. For other contaminants not descendent of recycled tires, artificial turf could act as an initial sink with gradual release over time. Kanematsu et al. (2009) and Nilsson et al. (2008) used mass spectra libraries and identified potential toxicants in rubber mulch leachate. However, to the authors' knowledge, only targeted approaches have been used when characterizing the crumb rubber on artificial turf fields. Non-specific sampling and analytical methods are still needed to fully characterize artificial turf fields.

PAHs are a subgroup of volatile organic compounds (VOCs) known as semi-volatile organic compounds (SVOCs) and generally have higher molecular weights and lower vapor pressures than VOCs. However, despite lower vapor pressures, SVOCs do vaporize and are typically present both in the gaseous phase and adsorbed onto surfaces and particulates (Xu and Zhang 2011). As such, contaminants can off-gas from crumb rubber infill, making chemicals available for inhalation by athletes and field users. Li et al. (2010) and Zhang et al. (2008) report that chemical off-gassing rates generally decrease as the field ages. Under most conditions, lower molecular weight PAHs are primarily in the gaseous phase, but importantly, PAHs with higher molecular weights are also partially present in the gaseous phase (Ramírez et al. 2011) and are often the largest contributor to PAH-associated health risks (Dye et al. 2006; Samburova et al. 2017). Researchers have observed that gas-phase PAHs can contribute heavily to the carcinogenic potency of PAH mixtures (Ramírez et al. 2011; Samburova et al. 2017). Thus measuring PAHs in the gaseous phase is relevant when assessing personal PAH exposure. Of environmental chemical transport processes, diffusion has been used as a baseline for total chemical movement, commonly referred to as flux (Fernandez et al. 2014). Flux on the unique artificial turf environment has not yet been measured in situ, and the research presented here is the first report of flux between soil and air on artificial turf. Artificial turf may be an important source of SVOCs, including PAHs, to air.

Passive sampling is an established method for measuring trace levels of contaminants and researchers often use passive samplers to detect chemicals in air environments (Huckins et al. 2002). Samplers can be made of various polymers that mimic uptake of biological membranes, such as polyethylene or silicone. Chemicals passively sorb into the material up to equilibrium concentrations, but environmental concentrations can still be determined when the samplers are still in the uptake phase. The polyethylene samplers have been used extensively in environmental monitoring and research, and the silicone samplers described in this work are identical to silicone wristbands in previous publications that measure personal exposure (e.g., Anderson et al. 2017; Dixon et al. 2019; O'Connell et al. 2014). Using two polymers concurrently enables a wider range of compounds to be sampled (O'Connell et al. 2014) and analyzed with multiple techniques.

This work samples three distinct artificial turf playing fields to demonstrate a range of chemical and flux profiles. Our objectives in this study were to use passive samplers to (1) identify gas-phase PAHs and OPAHs not previously associated with artificial turf by using a broad and targeted screen to assess both artificial turf and crumb rubber for 1530 chemicals, including several with known health effects; and (2) quantify PAH and OPAH flux between turf and the overlying air. Additionally, we demonstrate for the first time that silicone passive samplers can be used to quantify volatile and semivolatile organic chemicals from artificial turf and develop partitioning coefficients that can be used for silicone passive air sampling environmental assessment. This work will aide in future risk assessments by advancing and broadening the characterization of organic chemicals associated with artificial turf.

\section{Materials and methods}

\section{Chemicals and materials}

Target PAH analytes, deuterium-labeled internal standards, and extraction surrogates (Table S1) with purity $97 \%$ or greater were purchased from distributers as detailed previously (Anderson et al. 2015; O'Connell et al. 2013). PAHs fluorene-D10, pyrene-D10, benzo[b]fluoranthene-D12 (C/D/ $\mathrm{N}$ Isotope Inc.; Quebec, Canada), and the OPAH anthraquinone-D8 (Sigma-Aldrich; St. Louis, Missouri, USA) were used as performance reference compounds (PRCs) for determining in situ sampling rates. Low-density polyethylene (LDPE) passive samplers were constructed from lay-flat tubing purchased from Brentwood Plastics, Inc. (St. Louis, MO, USA). Silicone passive samplers (width, $1.3 \mathrm{~cm}$; inner diameter, $5.8 \mathrm{~cm}$ ) were purchased from 24hourwristbands.com (Houston, TX, USA). LDPE and silicone samplers were transported and stored in individual polytetrafluorethylene (PTFE) bags from Welch Fluorocarbon, (Dover, NH, USA).

\section{Site descriptions and sampling design}

We collected 20 passive samples concurrently; 10 LDPE samples and 10 silicone samples. Each LDPE sample was a 
composite of 5 LDPE strips, while each silicone sampler was one individual "wristband." We also collected crumb rubber samples that were each a composited from four locations within each field. The samples were collected on three different artificial turf fields in OR, USA: indoor, an indoor facility (turf field approximately 2 months old), outdoor A, an outdoor field surrounded by a rubberized track (approximately 2 years old); and outdoor B, an outdoor multi-use field (approximately 5 years old). Field managers add crumb rubber to fields on an as-needed basis.

Passive sampling devices were used to measure two matrices: air at an approximate height of $1.5 \mathrm{~m}$ and turf air, air immediately above and in close contact with turf (analogous to soil pore air). Paired air and turf air boxes, as described in Donald and Anderson (2017) were deployed at the three locations with triplicate equipment at outdoor A. Additional site details including weather conditions, photographs, and figures are provided in SI. All sampling equipment was set up concurrently and remained for 27 days in August and September 2016.

\section{Sample preparation and extraction}

\section{Low-density polyethylene (LDPE) passive samplers}

Passive samplers were prepared using strips of LDPE tubing as in Anderson et al. (2008). The strips were pre-conditioned in solvent baths, dried, and a solution containing performance reference compounds (PRCs) infused into each before heatsealing. Infusion with PRCs allows calculation of in situ air sampling rates and time-integrated air concentrations, as used in Donald and Anderson (2017) and preceding works. Inclusion of PRCs means that the environmental concentrations can be calculated before the samplers reach equilibrium with the environmental matrix. Post deployment, strips were cleaned in isopropanol and extracted with $n$-hexane after addition of surrogate extraction standards as in Donald and Anderson (2017). Five LDPE strips from each sampling box were composited for extraction. Internal standards were added to aliquots prior to instrumental analysis.

\section{Silicone passive samplers}

Silicone passive samplers were pre-conditioned in a vacuum oven, and $20 \mu \mathrm{L}$ of a PRC solution applied directly to the surface and air dried as in Anderson et al. (2017). Silicone samplers were thermally extracted onto Markes sorbent tubes (C3-AAXX-5304) using a Markes micro-chamber/thermal extractor. The tubes were fitted with Markes diffusion lock caps (difflock C-DL100) during analysis. Tubes used a Markes Unity 2/Ultra 2 Thermal Desorption System for introduction into the gas chromatographer with mass spectrometer detector (GC/MS). Conditions for thermal desorption are presented in SI, Table S5.

\section{Crumb rubber}

Twelve crumb rubber samples were collected from four different locations from each field and were composited into single representative sample for each field. Additionally, 4 crumb rubber samples were taken from "fresh" stock that had yet to be applied and composited into a sample. Samples were analyzed using the identical parameters as silicone samplers. Extraction and analysis was performed in triplicate for each crumb rubber sample, with approximately $50 \mathrm{mg}$ of crumb rubber used per sample.

\section{Instrumental analysis}

\section{LDPE passive samplers}

Extracts were analyzed using three separate analytical methods. Two are previously described methods for 62 PAHs and 19 OPAHs (Table 1). Briefly, PAH analysis was conducted using gas chromatography electron-impact/triple quadrupole mass spectrometry (GC/MS-MS, Agilent 7000C) with an Agilent PAH-select column (Anderson et al. 2015). Analysis for OPAHs was performed with GC/MS (Agilent 7890A and 5975C) with a DB5-MS column (O’Connell et al. 2013).

LDPE sampler extracts were also analyzed on a third analytical method for the presence or absence of 1530 chemicals using GC/MS with a DB5-MS column (Bergmann et al. 2018). This presence/absence screen, hereafter referred as the "1530 screen," uses mass spectral deconvolution software,

Table 1 Detected artificial turf-associated chemicals that are previously unreported in a 2016 literature survey conducted by USEPA (2016)

\begin{tabular}{ll}
\hline PAH method & \\
2-ethylnaphthalene & 2,6-diethylnaphthalene \\
1,6-dimethylnaphthalene & 3,6-dimethylphenanthrene \\
1,4-dimethylnaphthalene & Benzo[c]fluorene \\
2,4-dimethylnaphthalene & Triphenylene \\
1,5-dimethylnaphthalene & 6-methylchrysene \\
1,2-dimethylnaphthalene & Naphtho[1,2-b]fluoranthene \\
OPAH method & $\mathbf{1 5 3 0}$ screen \\
Chromone & b-citronellol \\
9-fluorenone & Benzyl salicylate \\
Xanthone & N,N-diethyl-m-toluamide \\
9,10-phenanthrenequinone & Ethiolate \\
9,10-anthraquinone & Pentachlorobenzene \\
Benzofluorenone & Triphenyl phosphate \\
& Benzyl benzoate \\
\hline
\end{tabular}


and the complete list of analytes is given at http://fses. oregonstate.edu/1530. Chemical concentrations in the 1530 screen are not quantified against calibration curves. Responses from blanks and quality control samples were compared to infer relative concentrations. Data was acquired using an Agilent 7890A GC and Agilent 5975C MS operated in in full scan mode with electron ionization using an Agilent DB-5MS column $(30 \mathrm{~m} \times 0.25 \mathrm{~mm})$. Inlet pressure was locked to the retention time of chlorpyrifos at $19.23( \pm 0.20)$ minutes. Full details are provided in Tables S3 and S4. Initial target compounds were obtained from the NIST 2008 mass spectral library with additional target compound retention time and reference library spectrum obtained through direct injections from single analyte solutions (Accustandard, New Haven CT). AMDIS version 2.66 (NIST), as part of the Deconvolution Reporting Software (DRS, Agilent), was used to de-convolute and identify additional peaks (Bergmann et al. 2018). AMDIS software parameters are given in Table S4. AMDIS integrated the identified peaks which were used for some general comparisons.

\section{Silicone passive samplers and crumb rubber}

Silicone samplers and crumb rubber were analyzed for 77 compounds, including PAHs, OPAHs, VOCs, flame retardants, triR-phosphates, polybrominated diphenyl ethers, pesticides, pharmacological chemicals, and consumer products, via GC/ MS following thermal extraction as per Table S5 using a Markes micro-chamber/thermal extractor. Samples were loaded into the extraction chamber and spiked with $2 \mu \mathrm{L}$ of a $50 \mathrm{ng} / \mu \mathrm{L}$ extraction surrogate solution. A sorbent tube packed with quartz wool, Tenax ${ }^{\circledR}$ TA, and carbograph 5TD was used. Samplers were thermally extracted by heating from an initial temperature of 25 to $50{ }^{\circ} \mathrm{C}$ held for $30 \mathrm{~min}$, then heated at the maximum heating rate to $250^{\circ} \mathrm{C}$ and held for $1.5 \mathrm{~h}$. Nitrogen was used as carrier gas at a flow rate of $40-50 \mathrm{~mL} / \mathrm{min}$.

After thermal extraction, tubes were fitted with Difflok caps, and were analyzed with an Agilent 6890N GC with an Agilent 5975B with triple axis detector MS equipped with a Markes series 2 Ultra auto sampler and Markes Unity 2 cold trap sample introduction system. Markes systems were controlled using Markes Maverick thermal desorption system control program, version 5.1.0. Agilent Chemstation E.02.00.493 was used to control Agilent components and to analyze data. Settings for sample acquisition are given in Table S5 and S6. Where overlap of PAH and OPAH compounds occur in two analysis methods, the value for the triple-quadrupole instrument is reported.

\section{Calculations}

Gas-phase concentrations of PAHs and OPAHs in air $\left(C_{\text {air }}\right)$ and turf air ( $\left.C_{\text {turf air }}\right)$ were determined from LDPE passive samplers using an empirical uptake model with PRCs as in situ calibration standards (Donald and Anderson 2017; Huckins et al. 2002). Details are provided in SI. Method detection limits (Table S1) were calculated separately for air and turf air, using average PRC retention per matrix and average temperature of deployment. Generally, detection limits increase from air to turf air, and increase with chemical volatility.

Quantitative flux (ng m${ }^{-2} \mathrm{~h}^{-1}$ ) between air and turf air was calculated for PAHs and OPAHs at each site when concentrations were above limits of quantitation in both matrices:

flux $=\frac{D^{T}}{\delta_{L}}\left(C_{\text {turf air }}-C_{\text {air }}\right)$

where $C_{\text {turf air }}$ is the concentration of a target chemical in air immediately at the turf surface ( $\mathrm{ng} \mathrm{m}^{-3}$ ) and $C_{\text {air }}$ is the concentration of a target chemical in air $\left(\mathrm{ng} \mathrm{m}^{-3}\right)$. The height of the boundary layer $\left(\delta_{\mathrm{L}}\right)$ was estimated at $0.001 \mathrm{~m}$. Temperature-corrected mass transfer coefficients $\left(D^{T}\right)$ were estimated from the $D^{T}$ of pyrene at $298 \mathrm{~K}$ as a reference (Table S1) (Donald and Anderson 2017).

\section{Statistical analysis}

Mean temperature and relative humidity comparisons were made using two-sided $t$-tests with serial correlation corrections. Uncertainty of flux calculations was estimated via propagation of error following the methods described in SI. Logarithms of air and turf air concentrations were compared using simple linear regression. Statistical analyses were performed in Microsoft Excel 2016 and JMP Pro 13.0.0.

\section{Quality control}

QC samples represented over $50 \%$ of all samples analyzed and included LDPE and silicone passive sampler construction blanks, field blank, trip blank for both deployment and retrieval as well as post-deployment cleaning blank, extraction blank and a field triplicate. Details and results of quality control samples are provided in SI. Instrumental limits of quantitation (LOQs) were calculated in accordance with other methods in our laboratory and described previously (Anderson et al. 2015; Bergmann et al. 2018).

\section{Results and discussion}

\section{Environmental concentrations of PAHs and OPAHs in turf}

Among ten turf air and pore-air LDPE samples, we detected 44 PAHs and 7 OPAHs (Fig. 1). Higher molecular 


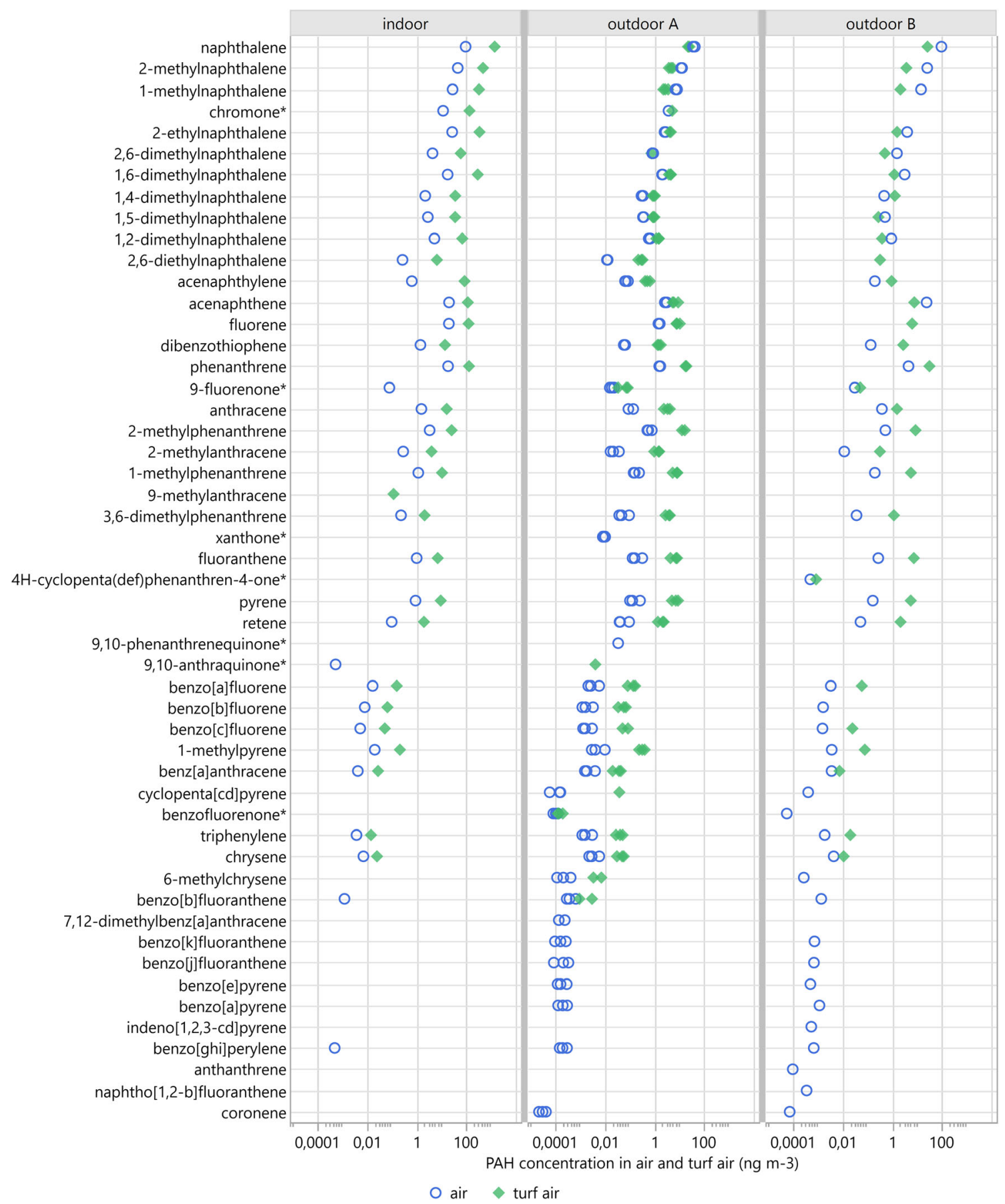

Fig. 1 Concentrations of PAHs and OPAHs in air and turf air. OPAHs are indicated with asterisks. Triplicate samples were collected at outdoor A. Compounds are ordered by $\log \mathrm{K}_{\mathrm{ow}}$, from low to high

weight chemicals were more frequently detected in air, even though air has slightly lower detection limits (Table S1). The indoor site, the newest field sampled, had the highest concentrations, with average PAH and OPAH levels in both air and turf air 20- and 13-fold greater than at outdoor A and outdoor B, respectively. Indoor fields, particularly those with poor ventilation, have documented higher levels of air contaminants (European Chemicals Agency 2017).
Samples at outdoor A were collected in triplicate, and variance across target analytes present in both matrices was similar between air (average RSD 26\%) and turf air (average RSD $21 \%$ ). This contrasts with the initial demonstration of the flux passive sampling equipment in which variance in soil air (RSD 40\%) far exceeded the variance in air (RSD 8\%; Donald and Anderson 2017). These differences in variance may reflect the relative homogeneity of an artificial turf field versus natural settings. 
Twelve detected PAHs had not been reported previously in work related to artificial turf (Table 1; USEPA 2016), including many alkyl-naphthalenes. The presence of these alkylatednaphthalenes associated with artificial turf is noteworthy for risk assessment considerations. The risk of environmental PAH exposure has not been fully characterized due in part to a lack of adequate exposure data for alkylated PAHs, and in aquatic studies, mounting evidence suggests that alkylated PAHs may be more toxic than parent PAHs, perhaps due both to bioavailability and toxic potency of alkylated PAHs (Han et al. 2014). Han (and references therein) illustrated an 18-fold increase in toxicity for alkylated-naphthalenes over naphthalene in copepods. While more studies are needed to assess human toxicity, these results demonstrate the importance of analyzing large numbers of chemicals in human exposure scenarios.

One PAH not previously reported was benzo[c]fluorene, with an estimated carcinogenic potency 20 times greater than benzo[a]pyrene (USEPA 2010). Benzo[c]fluorene was detected in all LDPE samplers at all sites. On the three sampled fields, turf air concentrations were higher than air concentrations, indicating that benzo[c]fluorene was volatilizing from turf. Independent of turf, Yagishita et al. (2015) found benzo[c]fluorene in the gas phase in a recent atmospheric study in Japan, and reported that $44 \%$ of benzo[c]fluorene was in the gas phase and a large contributor to the atmospheric carcinogenic risk of PAHs.

Many PAHs in tires are from the addition of highlyaromatic oils (HA-oils) during manufacturing (Sadiktsis et al. 2012; Schiliro et al. 2013). HA-oils formerly contained between 10 and $30 \%$ PAHs by weight, but high-PAH HA-oils have been phased out of European Union (EU) countries after directive 2005/69/EC beginning in 2010. It is expected that tire producers worldwide will increasingly use alternative, low-PAH HA-oils (Cheng et al. 2014). Tires are also a documented source of carcinogenic, 6-ringed dibenzopyrene PAHs to the environment, but levels are expected to decline as highPAH HA-oils continue to be phased out (Sadiktsis et al. 2012). This study sampled both volatile and semi-volatile gas-phase contaminants, and most PAHs observed were lower-MW PAHs. We did not detect the carcinogenic dibenzopyrenes described in Sadiktsis et al. (2012) where crumb from tires containing HA-oils was analyzed. If present, such 6-ringed dibenzopyrenes would likely be highly associated with particles and therefore present in the gas-phase at low levels.

Pyrene and benzo[ghi]perylene are major PAH components in tires, and have been documented as major components in artificial turf crumb rubber as well (Sadiktsis et al. 2012). Pyrene was present in all air, turf air and crumb rubber samples in this study. Additionally, the less-volatile benzo[ghi]perylene was detected in all air samples above turf in this study, but was below limits of detection in turf air.
We detected six OPAHs not previously reported at artificial turf fields (Table 1). Previous reports are limited to three OPAHs: $6 \mathrm{H}-\mathrm{benzo}[\mathrm{cd}] \mathrm{pyren}-6-\mathrm{one}, 4 \mathrm{H}-$ cyclopenta[def]phenanthrene-4-one, and 2-ethyl-9,10-anthraquinone (Kanematsu et al. 2009; USEPA 2016). Two of these were included in our analysis, and we detected $4 \mathrm{H}$ cyclopenta[def]phenanthrene-4-one, but not $6 \mathrm{H}-$ benzo[cd]pyren-6-one. Compared to the PAHs, the toxicity of OPAHs is less well-studied (Lundstedt et al. 2007). OPAHs may have more mutagenic potential than their corresponding parent PAHs, and some OPAHs need not be metabolically activated to induce toxicity (Lundstedt et al. 2007). Knecht et al. (2013) screened 38 OPAHs for morphological malformations using the embryonic zebrafish model, and found 9,10-phenanthraquinone to be one of the most toxic OPAHs, followed closely by benzofluorenone. Benzofluorenone is also a potent inhibitor of the CYP1A1 enzyme, indicating that this OPAH is as toxicologically relevant as the more studied PAHs (Wincent et al. 2016). These newly reported PAHs and OPAHs may be considered as potential toxicants in future human risk assessments of artificial turf field users.

Numerous studies report concentrations of PAHs associated with particles; however, to the authors' knowledge, only one previous report gives gas-phase concentrations on an artificial turf field. Dye et al. (2006) used active samplers to collect the gas-phase concentration in three indoor facilities with artificial turf. Air data from indoor turf in the research here agrees well with results in Dye et al. (2006) (Fig. S14), suggesting that the disparate sampling methods are comparable. Dye et al. (2006) also includes particle-phase (PM10) PAH concentrations as a separate measurement. Comparing these two phases (Fig. S15), PM10-bound and gas-phase, we infer that over $97 \%$ of measured PAHs were in the gas-phase. Generally, the low-molecular weight, volatile chemicals were predominantly present in the gas-phase, while PAHs with log $\mathrm{K}_{\mathrm{oa}}$ approximately 9 or greater were mostly associated with particles. Similar trends are observed beyond the artificial turf environment (Thang et al. 2014). Gas-phase contaminants are bioavailable and can enter biological membranes when inhaled or contacted. Contaminants adsorbed to particles are less bioavailable, and particle size affects penetration into the lungs (European Chemicals Agency 2017). The current work gives the first gas-phase concentrations around outdoor artificial turf fields to date (USEPA 2016).

\section{Concentrations in crumb rubber}

Crumb rubber stock and the 2-month-old indoor field crumb rubber samples had similar numbers of VOC/SVOC detections; 35 and 38, respectively (Fig. 2). Crumb rubber stock had more chemicals than either of the outdoor samples, 35 versus 31 and 19 chemicals respectively. Compared with the 
stock crumb rubber, the outdoor A and B samples were mostly missing the most volatile compounds (decanes and the naphthalenes) which have volatilized into air. Outdoor B crumb rubber had the fewest chemicals detected and was also missing phenanthrene, substituted phenanthrenes, and many higher molecular weight SVOCs like benz[b or c]fluorene, chrysene, triphenylene, or benzo[a]pyrene (see Fig. 2). Crumb rubber is an important contribution to the chemicals measured and could pose a potential inhalation exposure hazard.

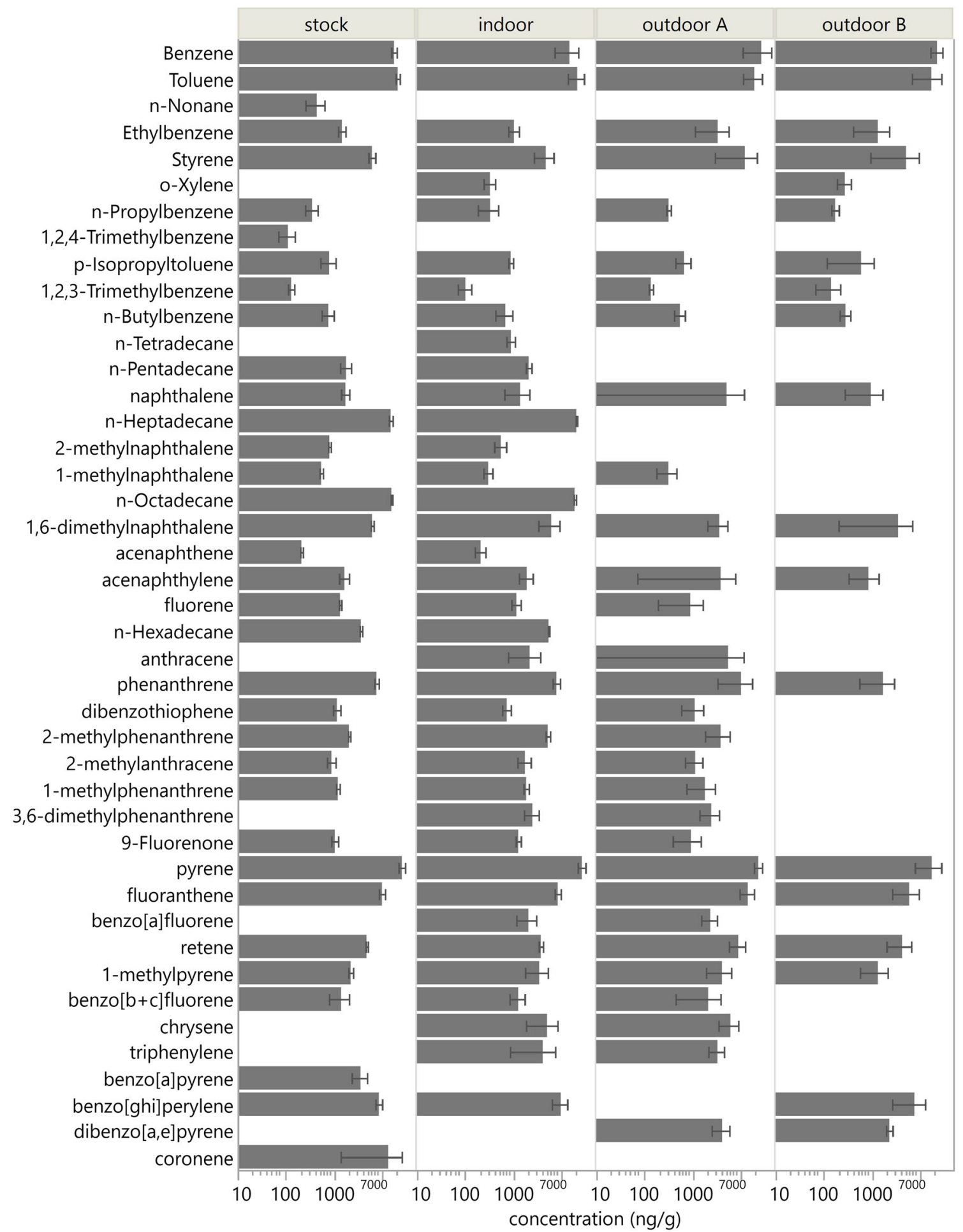

Fig. 2 Average concentrations $(n=3)$ in crumb rubber samples. Each sample was composited from 4 locations per field and analyzed in triplicate. Stock crumb rubber was pulled from stock and has never been applied to fields 
Field managers occasionally add fresh crumb rubber to fill in more worn sections of the field, and we do not have a record of these applications on any of the sampled fields. A typical soccer field contains between 75,000 and $112,500 \mathrm{~kg}$ of crumb rubber and the small additions are unlikely to affect the overall character of the field. We aimed to avoid biased samples by compositing four locations on each field.

\section{Presence/absence of 1530 chemicals}

The LDPE samplers were screened for the presence or absence of 1530 additional compounds. Nineteen chemicals were detected beyond the PAHs and OPAHs (Fig. 3) including seven that have not been previously reported (Table 1) (USEPA 2016). Two phthalates were present in small amounts in the procedural blanks, but are included in Fig. 3 nonetheless because responses were more than 500-fold greater in field samples than in procedural blanks (bis(2-ethylhexyl)phthalate and di-n-butylphthalate, Table S9).
Phthalates detected in the present work have been reported in previous analyses of crumb rubber (Llompart et al. 2013), playground material (Celeiro et al. 2014), and air at playing fields (European Chemicals Agency 2017; USEPA 2016). Four phthalates are recognized as reproductive toxicants by the Registration, Evaluation, Authorization and Restriction of Chemicals (REACH) directive. A recent risk analysis of these four phthalates (bis(2-ethylhexyl)phthalate, di-nbutylphthalate, butyl benzylphthalate, and diisobutylphthalate) concluded that concentrations are below levels that would lead to health problems in players and workers (European Chemicals Agency 2017). The present work confirms the presence of these phthalates on the sampled fields.

Several personal care products were detected using the 1530 screen in both air and turf air samplers. The chemical $b$-citronellol is a component of perfumes and essential oils of various plants (Ribeiro-Filho et al. 2016). Benzyl salicylate, a scent compound (Lapczynski et al. 2007) was
Fig. 3 Detections in the presence/ absence (1530) screen, where a shading indicates the chemical is present. At indoor and outdoor B, black indicates presence. Samples at outdoor A were collected in triplicate; the greyscale corresponds to the frequency of detection from 1 to 3

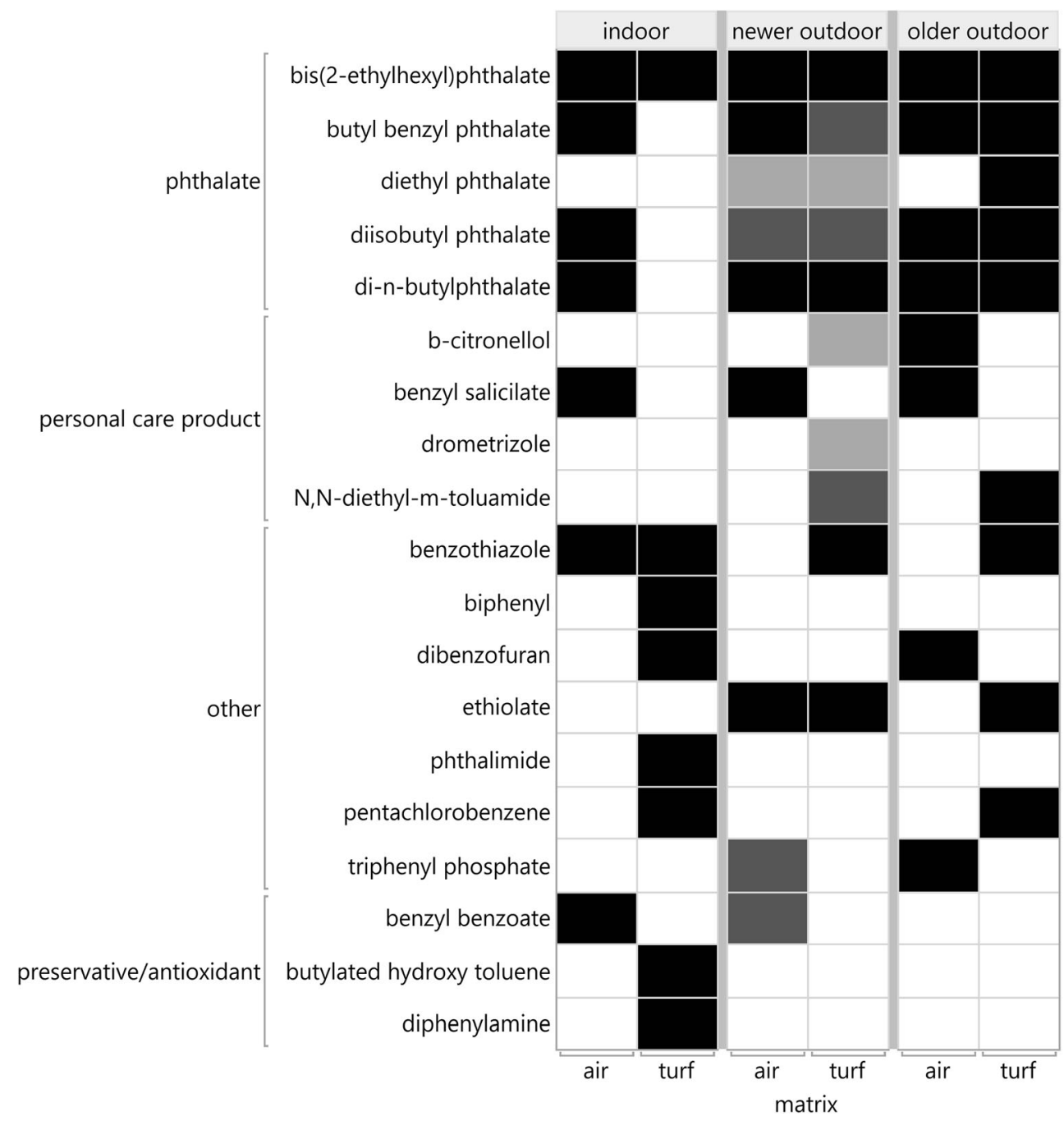




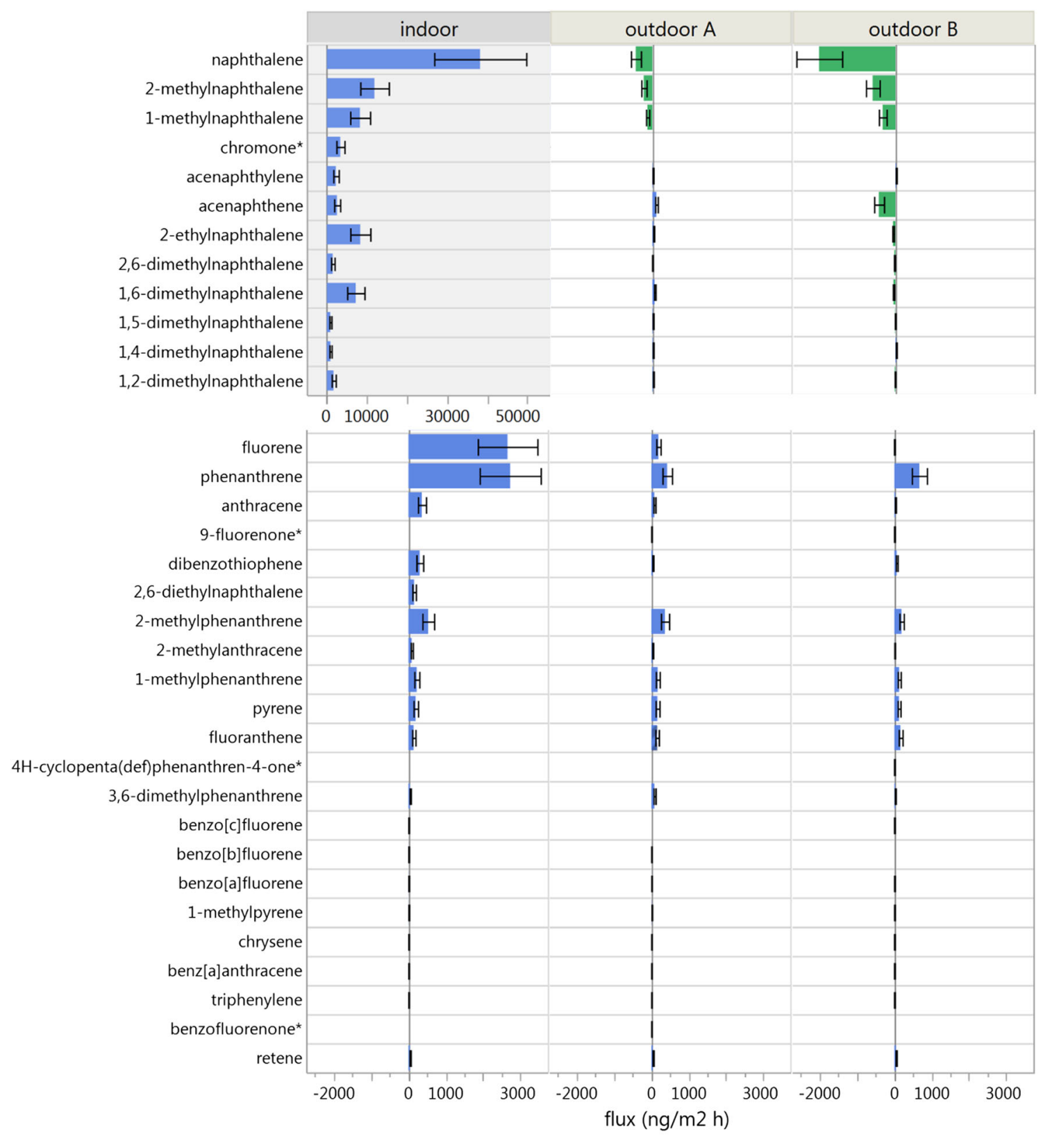

Fig. 4 Magnitude and direction of PAH and OPAH flux. Error bars show uncertainty determined via propagation of error. The scale in the top left is reduced to larger values. Chemicals are listed in order of molecular

present in all air samples, but absent in all turf air samples. Drometrizole, an ultraviolet light absorber used in sunscreen products (Antoniou et al. 2008) and plastic polymers (Lygre et al. 1999), was found in one turf air sampler. This chemical has previously been detected in crumb rubber leachate (Nilsson et al. 2008), and we cannot distinguish whether our detection is due to personal care product usage or as an antioxidant additive in sourced tires used in the crumb rubber. The common insect repellent N,N-diethyl-m-toluamide (DEET) was deposition

volatilization

weight, from low to high. OPAHs are indicated with asterisks. Flux was not determined if a chemical was below limit of detection in either air or turf air

found in turf air samplers. With the possible exception of drometrizole, personal care products such as these are unlikely to be present in fresh crumb rubber; therefore, their detections likely stem from field users rather than the artificial turf. Personal care products found in turf air support the hypothesis that artificial turf can act an initial sink to naive chemicals, with gradual off-gassing over time.

In addition, we observed several other chemicals, seven of which have not been reported previously to be associated with 


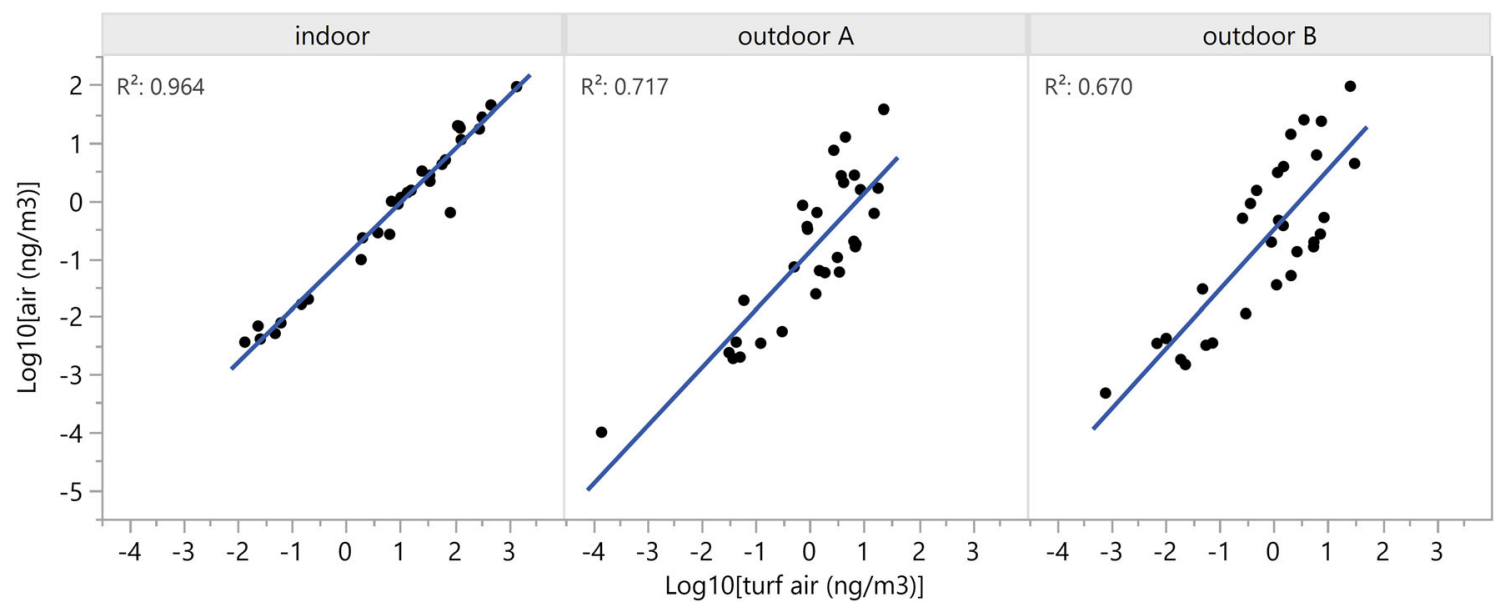

Fig. 5 Turf air concentrations correlated with air concentrations fit is greatest at indoor, the location with more volatilization and likely less convolution from air movement and temperature extremes

artificial turf, tires, or crumb rubber (Table 1). Ethiolate, a dithiocarbamate herbicide believed to be no longer in use (World Health Organization 2009), has not been previously associated. However, dithiocarbamates are used as vulcanizing agents in tire production (ChemRisk Inc. and DIK Inc. 2008) and we hypothesize this detection represents a structurally-similar dithiocarbamate constituent of tires. Pentachlorobenzene is a persistent organic pollutant included in the Stockholm Convention (Bailey et al. 2009). Pentachlorobenzene was seen in two samples, in turf air from the indoor newest field and in turf air from the oldest outdoor field. Pentachlorobenzene can also be emitted from biomass burning (Bailey et al. 2009), and regional wildfires around the sampling period are a potential source. Finally, triphenyl phosphate is a flame retardant and is used in hydraulic fluids and plasticizers (Hou et al. 2016). Triphenyl phosphate detections were observed only in air, and only at the older and outdoor fields, and suggest that artificial turf is not the primary source of this chemical.

At the outdoor fields, we detected benzothiazole only in turf air, as in previous reports where samples were collected 6 in. $(15 \mathrm{~cm})$ above turf (Connecticut Department of Public Health 2010; Ginsberg et al. 2011). Benzothiazole levels were substantially higher indoors than outside in previous studies (Connecticut Department of Public Health 2010; Ginsberg et al. 2011). Similarly, in our work, benzothiazole was above detection limits in both air and turf pore air at the indoor field, but only detectable in turf air at the outdoor fields, generally suggesting lower levels outdoors. Phthalimide, another chemical associated with rubber vulcanization, was detected in one turf air sampler and has been reported previously in leachate from artificial turf (USEPA 2016). Preservatives and antioxidants like butylated hydroxy toluene and diphenylamine are known components of tires, although benzyl benzoate has not previously been reported in artificial turf literature (USEPA 2016).

\section{Flux of PAHs and OPAHs}

Flux varied substantially among the three fields (Fig. 4) where flux was evaluated for 35 PAHs and OPAHs at all sites in which both air and turf air measurements were above limit of detection. Complete flux values with uncertainty determined via propagation of error are given in Table S10. Naphthalene had the highest measured rate of volatilization (indoor site, $38,000 \mathrm{ng} \mathrm{m}^{-2} \mathrm{~h}^{-1}$ ), and the highest rate of deposition (outdoor $\mathrm{B},-2000 \mathrm{ng} \mathrm{m}^{-2} \mathrm{~h}^{-1}$ ). All flux values at the indoor site were positive, indicating volatilization from turf air into the air, with an average rate of $3000 \mathrm{ng} \mathrm{m}^{-2} \mathrm{~h}^{-1}$. In comparison, only higher molecular-weight, less-volatile chemicals were volatilizing at the outdoor sites. The more volatile chemicals naphthalene and 1- and 2-methylnaphthalene were depositing at both outdoor $\mathrm{A}$ and $\mathrm{B}$, while the slightly-heavier dimethylnaphthalenes were generally depositing only at the oldest of the three sites, outdoor B. When measurable, OPAHs were volatilizing; however, only chromone was significantly volatilizing. Profiles of PAH/OPAH flux agrees with previous evidence that off-gassing relates to the age of the field (Li et al. 2010). Compared to the newest field, the two older fields appear to be acting as a sink for the more volatile chemicals. Additional sampling is needed to confirm these trends, though we do mention these details to highlight possible reasons for flux differences.

The relationship between turf and overlying air can also be represented by a simple correlation (Fig. 5). We observed correlations $(p$ value $<0.05)$ at each field, although the strength of correlation varied. The newest field, indoor, had the strongest correlation $\left(R^{2}=0.964\right)$, indicating that volatilization from turf strongly affects concentrations in the overlying air at this site. Slightly less strong correlations were observed at outdoor $\mathrm{A}\left(R^{2}=0.717\right)$ and outdoor $\mathrm{B}\left(R^{2}=0.670\right)$, providing evidence that the contribution of volatilization at the two older, outdoor sites is likely convoluted by additional 
Table $2 \quad \log \mathrm{K}_{\mathrm{sa}}$ values for silicone and LDPE (low-density polyethylene)

\begin{tabular}{|c|c|c|c|c|c|}
\hline Chemical & $\log$ Koa & $\log$ Ksa LDPE & $\begin{array}{l}\text { log Ksa Anderson } \\
\text { et al. } 2017 \text { silicone }\end{array}$ & $\begin{array}{l}\text { Predicted log Ksa } \\
\text { this study silicone }\end{array}$ & $\begin{array}{l}\text { Percent difference between } \\
\text { log Ksa (\%) (Anderson et al. } 2017 \\
\text { and this study) }\end{array}$ \\
\hline Naphthalene & 5.05 & 4.43 & 5.9 & 5.3 & 11 \\
\hline 2-methyl-Naphthalene & 5.53 & 5.07 & 6.1 & 5.9 & 3.2 \\
\hline 1-methyl-Naphthalene & 5.55 & 5.09 & 6.1 & 5.9 & \\
\hline 2-ethyl-Naphthalene & 6.04 & 5.58 & & 6.5 & \\
\hline 2,6-dimethyl-Naphthalene & 5.89 & 5.58 & & 6.4 & \\
\hline 1,4-Dimethylnaphthalene & 6.17 & 5.65 & & 6.7 & \\
\hline 1,5-Dimethylnaphthalene & 6.22 & 5.66 & & 6.8 & \\
\hline 1,2-dimethylnaphthalene & 5.89 & 5.58 & & 6.4 & \\
\hline 1,8-Dimethylnaphthalene & 6.22 & 5.52 & & 6.8 & \\
\hline 2,6-Diethylnaphthalene & 6.59 & 6.48 & & 7.2 & \\
\hline Acenaphthylene & 6.27 & 6.20 & 6.2 & 6.8 & 9.8 \\
\hline Acenaphthene & 6.04 & 5.46 & 6.3 & 6.6 & 3.9 \\
\hline Fluorene & 6.59 & 6.00 & 6.4 & 7.2 & 12 \\
\hline Dibenzothiophene & 7.24 & 7.03 & & 8.1 & \\
\hline Phenanthrene & 7.22 & 6.86 & 6.7 & 8.0 & 18 \\
\hline Anthracene & 7.09 & 6.85 & 6.6 & 7.9 & 18 \\
\hline 2-Methylphenanthrene & 7.50 & 7.30 & 6.8 & 8.4 & 21 \\
\hline 2-methylanthracene & 7.64 & 7.47 & & 8.6 & \\
\hline 1-Methylphenanthrene & 7.78 & 7.57 & 6.9 & 8.7 & 24 \\
\hline 9-Methylanthracene & 7.87 & 7.56 & & 8.9 & \\
\hline 3,6-Dimethylphenanthrene & 8.03 & 7.97 & & 9.1 & \\
\hline Fluoranthene & 8.60 & 8.50 & 7.2 & 9.8 & 31 \\
\hline 2,3-Dimethylanthracene & 8.03 & 7.97 & & 9.1 & \\
\hline 9,10-Dimethylanthracene & 8.28 & 8.27 & & 9.4 & \\
\hline Pyrene & 8.19 & 8.16 & 7.0 & 9.3 & 28 \\
\hline Retene & 8.70 & 8.83 & & 9.9 & \\
\hline Benzo(a)fluorene & 8.36 & 8.50 & & 9.5 & \\
\hline Benzo(b)fluorene & 9.57 & 8.95 & & 11.0 & \\
\hline Benzo(c)fluorene & 8.37 & 8.25 & & 9.5 & \\
\hline 1-Methylpyrene & 8.91 & 8.85 & & 10.2 & \\
\hline Benz(a)anthracene & 9.07 & 9.45 & & 10.4 & \\
\hline Cyclopenta(c,d)pyrene & 10.15 & 10.14 & & 11.8 & \\
\hline Triphenylene & 10.69 & 9.13 & & 12.4 & \\
\hline Chrysene & 9.48 & 9.52 & & 10.9 & \\
\hline 6-methylchrysene & 9.72 & 9.79 & & 11.2 & \\
\hline 5-methylchrysene & 9.72 & 9.79 & & 11.2 & \\
\hline Benzo(b)fluoranthene & 10.35 & 10.27 & & 12.0 & \\
\hline 7,12-Dimethylbenz(a)anthracene & 9.61 & 9.42 & & 11.1 & \\
\hline Benzo(k)fluoranthene & 10.73 & 10.67 & & 12.5 & \\
\hline Benzo(j)fluoranthene & 10.59 & 10.67 & & 12.3 & \\
\hline Benzo(e)pyrene & 11.35 & 11.08 & & 13.3 & \\
\hline Benzo(a)pyrene & 10.86 & 10.70 & & 12.6 & \\
\hline Perylene & 10.08 & 10.84 & & 11.7 & \\
\hline Indeno(1,2,3-c,d)pyrene & 11.55 & 12.18 & & 13.5 & \\
\hline Dibenz(a,h)anthracene & 11.78 & 11.67 & & 13.8 & \\
\hline Picene & 11.81 & 12.11 & & 13.9 & \\
\hline Benzo(ghi)perylene & 11.50 & 12.10 & & 13.5 & \\
\hline
\end{tabular}


Table 2 (continued)

\begin{tabular}{|c|c|c|c|c|c|}
\hline Chemical & $\log$ Koa & $\log \mathrm{Ksa}$ LDPE & $\begin{array}{l}\text { log Ksa Anderson } \\
\text { et al. } 2017 \text { silicone }\end{array}$ & $\begin{array}{l}\text { Predicted log Ksa } \\
\text { this study silicone }\end{array}$ & $\begin{array}{l}\text { Percent difference between } \\
\text { log Ksa (\%) (Anderson et al. } 2017 \\
\text { and this study) }\end{array}$ \\
\hline Anthanthrene & 12.31 & 12.60 & & 14.5 & \\
\hline Naptho[1,2-b]fluoranthene & 12.77 & 13.11 & & 15.1 & \\
\hline Naphtho[2,3-j]fluoranthene & 12.77 & 13.11 & & 15.1 & \\
\hline Dibenzo(a,e)fluoranthene & 12.77 & 13.11 & & 15.1 & \\
\hline Dibenzo(a,l)pyrene & 13.20 & 13.64 & & 15.6 & \\
\hline Naphtho[2,3-k]fluoranthene & 12.77 & 13.11 & & 15.1 & \\
\hline Naphtho[2,3-e]pyrene & 12.77 & 13.11 & & 15.1 & \\
\hline Dibenzo(a,e)pyrene & 13.20 & 13.64 & & 15.6 & \\
\hline Coronene & 13.70 & 14.12 & & 16.2 & \\
\hline Dibenzo(e,l)pyrene & 12.77 & 13.11 & & 15.1 & \\
\hline Naptho[2,3-a]pyrene & 12.77 & 13.11 & & 15.1 & \\
\hline Benzo(b)perylene & 12.77 & 13.11 & & 15.1 & \\
\hline Dibenzo(a,i)pyrene & 12.77 & 13.11 & & 15.1 & \\
\hline Dibenzo(a,h)pyrene & 12.77 & 13.11 & & 15.1 & \\
\hline
\end{tabular}

outdoor sources and potentially greater air movement. Similar correlation analyses have been conducted, albeit sparingly. Cabrerizo et al. (2011) report high correlations $\left(R^{2}=0.63\right.$ and 0.76 ) between air fugacity and soil fugacity where volatilization of organochlorine pesticides occurs at background sites, but weaker correlations $\left(R^{2}=0.32\right.$ and insignificant) at sites with deposition signatures. In a similar approach, Bidleman and Leone (2004) point to good correlations between soil concentrations and overlying air concentrations ( $R^{2}$ up to 0.73 ) as evidence of volatilization. The strength of correlation observed at the indoor site exceeds these previous reports of volatilization from soil, and we hypothesize that the strength of this correlation will decrease over time as the field age.

\section{Silicone-air partitioning coefficient}

Commonly, new techniques are calibrated against existing technologies. Khairy and Lohmann (2014) co-deployed LDPE passive samplers with established active samplers to, in part, determine sampler-air partition coefficients. These partition coefficients are used to calculate environmental air concentrations from passive sampler concentrations. Similarly, we co-deployed silicone samplers alongside the more established LDPE. Numerous types of silicone polymer have been used in organic pollutant research (Smedes et al. 2009). O'Connell et al. (2014) co-deployed LDPE and different types of silicone to illustrate that the properties of target compounds should be considered when selecting a polymer in passive sampling studies. Co-deployment of conventional and new samplers is valuable for gaining insight into the characteristics of new sampling technologies. Further, the previous report that used active samplers (Dye et al. 2006) have results similar to our LDPE results, providing additional support of LDPE values used in the paired approach for assessing silicone-air portioning coefficients. In addition to environmental sampling, silicone samplers in the present study have been used as wearable samplers (wristbands) in numerous applications to detect personal chemical exposures, e.g. (Dixon et al. 2019; O'Connell et al. 2014).

Side-by-side deployment of passive samplers of two materials allowed for calculation of silicone-air partition coefficients $\left(K_{\text {silicone-air }}\right)$ :

$K_{\text {silicone-air }}=\frac{C_{\text {silicone }}}{C}$

where $C_{\text {silicone }}$ is the concentration in silicone and $C$ is the concentration in air or turf air determined with LDPE samplers. Values for $K_{\text {silicone- air }}$ of chemicals were determined for chemicals at equilibrium, as inferred from PRC dissipation data.

Our silicone-air partition coefficients $\left(K_{\text {silicone- air }}\right)$ determinations are similar to a previous report of silicone-air partition coefficients ( $K_{\text {silicone-air }}$ ) in Anderson et al. (2017); the percentage difference ranges from 0.97 to $11.4 \%$ with larger prediction intervals (Table 2 and Fig. 6). In Anderson et al. (2017), the silicone was worn on participants' wrists, so sampling occurred at near-constant temperatures. In contrast, average temperatures in this turf study ranged between 20.5 and $25.2{ }^{\circ} \mathrm{C}$, and though this is a small range, even small differences in temperature can result in large changes in partitioning. A $10{ }^{\circ} \mathrm{C}$ increase in temperature is expected to 
Fig. $6 \mathrm{~K}_{\mathrm{sa}}$ determination as determined in the present study (red line) and Anderson et al. (2017) (blue line)

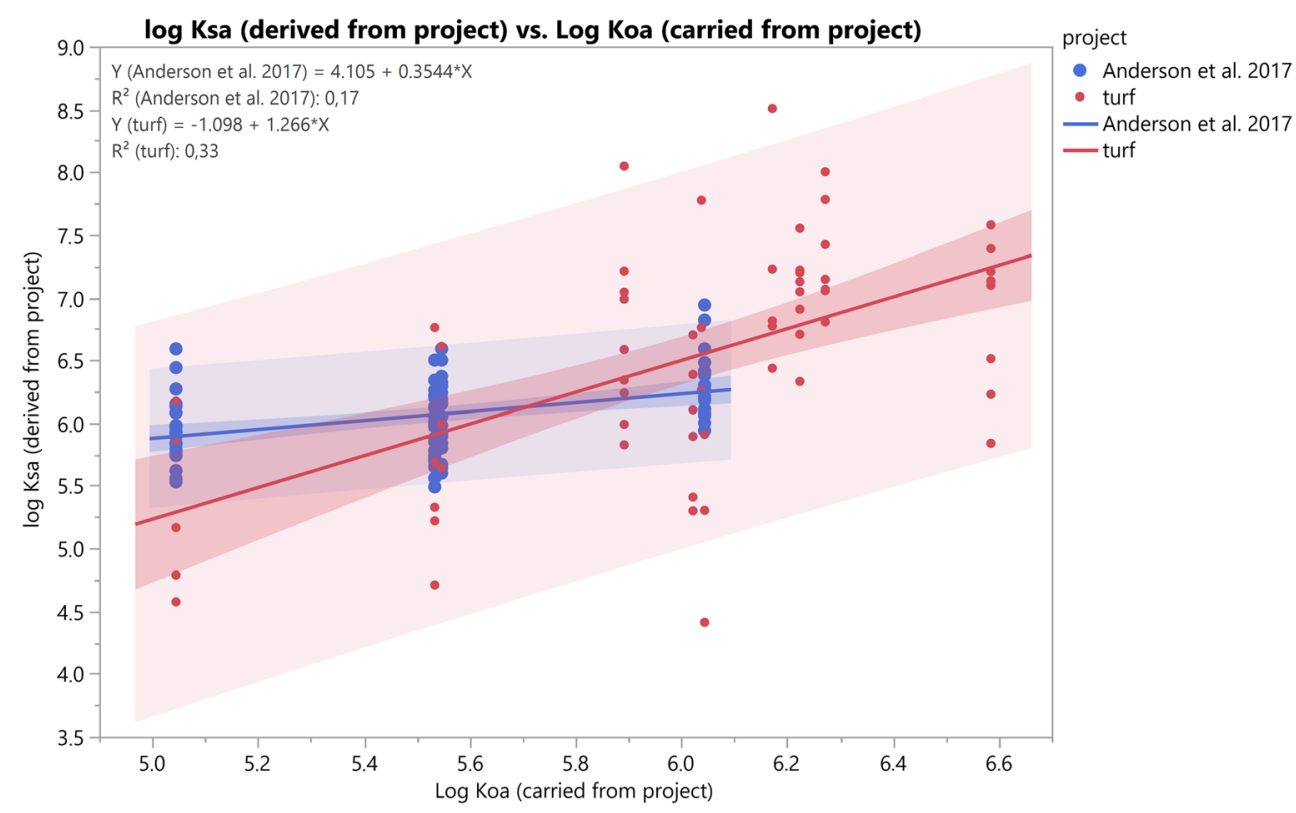

decrease $K_{\text {silicone - air }}$ by twofold. We propose that the variability in our prediction of $K_{\text {silicone-air }}$ can be attributed to the differences in environmental conditions. In future work, this information can be combined to understand the contribution of vapor-phase contaminants in environmental and personal exposure. For example, personal sampling using the silicone samplers may reveal unique exposure patterns that stationary monitors cannot discern (Shen et al. 2014), such as field users participating in different sports or positions.

\section{Limitations}

This study does not incorporate fields with a wide range of ages, adjacent contaminant sources, geographic location, artificial turf manufacturers, or use patterns. The trends observed with field age and indoor/outdoor locations will need to be validated with additional sampling on fields with a range of ages, geographic locations and manufacturers. We sampled during the warmest days of the year. As chemical volatility increases with temperature, we expect lower volatilization rates in cooler temperatures, all else constant. The detection of a chemical in an air sample does not necessarily indicate it derives from artificial turf. Detections in the self-contained turf air sampling boxes are more likely associated with artificial turf and infill. The passive sampling technologies and range of analytical methods demonstrated here can help provide critical missing information for researchers determining how artificial turf-associated chemical exposures may contribute to adverse health outcomes.

Acknowledgements The authors thank Gary Points, Holly Dixon, Jessica Scotten, Lane Tidwell, and Amber Barnard for field and laboratory support and the field managers for permission and assistance.
Funding information This work was supported by the National Institute of Environmental Health Sciences (NIEHS) award number P42 ES016465 and the associated Chemistry Facility Core, P30 ES000210. CE Donald was supported in part by NIEHS Training Grant Fellowship T32ES007060 from the National Institutes of Health (NIH).

Open Access This article is distributed under the terms of the Creative Commons Attribution 4.0 International License (http:// creativecommons.org/licenses/by/4.0/), which permits unrestricted use, distribution, and reproduction in any medium, provided you give appropriate credit to the original author(s) and the source, provide a link to the Creative Commons license, and indicate if changes were made.

Publisher's note Springer Nature remains neutral with regard to jurisdictional claims in published maps and institutional affiliations.

\section{References}

Anderson KA, Sethajintanin D, Sower GJ, Quarles L (2008) Field trial and modeling of uptake rates of in situ lipid-free polyethylene membrane passive sampler. Environ Sci Technol 42:4486-4493. https:// doi.org/10.1021/es702657n

Anderson KA, Szelewski MJ, Wilson G, Quimby BD, Hoffman PD (2015) Modified ion source triple quadrupole mass spectrometer gas chromatograph for polycyclic aromatic hydrocarbon analyses. J Chromatogr A 1419:89-98. https://doi.org/10.1016/j.chroma. 2015.09.054

Anderson KA, Points Iii GL, Donald CE et al (2017) Preparation and performance features of wristband samplers and considerations for chemical exposure assessment. J Expo Sci Environ Epidemiol 27: 551-559. https://doi.org/10.1038/jes.2017.9

Antoniou C, Kosmadaki MG, Stratigos AJ, Katsambas AD (2008) Sunscreens - what's important to know. J Eur Acad Dermatol Venereol 22:1110-1119. https://doi.org/10.1111/j.1468-3083.2007. 02580.x

Bailey RE, van Wijk D, Thomas PC (2009) Sources and prevalence of pentachlorobenzene in the environment. Chemosphere 75:555-564. https://doi.org/10.1016/j.chemosphere.2009.01.038 
Bergmann AJ, Points GL, Scott RP, Wilson G, Anderson KA (2018) Development of quantitative screen for 1550 chemicals with GCMS. Anal Bioanal Chem 410:3101-3110. https://doi.org/10.1007/ s00216-018-0997-7

Bidleman TF, Leone AD (2004) Soil-air exchange of organochlorine pesticides in the Southern United States. Environ Pollut 128:49 57. https://doi.org/10.1016/j.envpol.2003.08.034

Cabrerizo A, Dachs J, Jones KC, Barceló D (2011) Soil-air exchange controls on background atmospheric concentrations of organochlorine pesticides. Atmos Chem Phys 11:12799-12811. https://doi.org/ 10.5194/acp-11-12799-2011

Celeiro M, Lamas JP, Garcia-Jares C, Dagnac T, Ramos L, Llompart M (2014) Investigation of PAH and other hazardous contaminant occurrence in recycled tyre rubber surfaces. Case-study: restaurant playground in an indoor shopping centre. Int J Environ Anal Chem 94:1264-1271. https://doi.org/10.1080/03067319.2014. 930847

ChemRisk Inc., DIK Inc. (2008) State of knowledge report for tire materials and tire wear particles.

Cheng H, Hu Y, Reinhard M (2014) Environmental and health impacts of artificial turf: a review. Environ Sci Technol 48:2114-2129. https:// doi.org/10.1021/es4044193

Connecticut Department of Public Health (2010) Human health risk assessment of artificial turf fields based upon results from five fields in Connecticut. Program in environmental and occupational health assessment

Dixon HM, Armstrong G, Barton M, Bergmann AJ, Bondy M, Halbleib ML, Hamilton W, Haynes E, Herbstman J, Hoffman P, Jepson P, Kile ML, Kincl L, Laurienti PJ, North P, Paulik LB, Petrosino J, Points GL III, Poutasse CM, Rohlman D, Scott RP, Smith B, Tidwell LG, Walker C, Waters KM, Anderson KA (2019) Discovery of common chemical exposures across three continents using silicone wristbands. R Soc Open Sci 6:181836. https://doi.org/10.1098/rsos. 181836

Donald CE, Anderson KA (2017) Assessing soil-air partitioning of PAHs and PCBs with a new fugacity passive sampler. Sci Total Environ 596-597:293-302. https://doi.org/10.1016/j.scitotenv.2017.03.095

Dye C, Bjerke A, Schmidbauer N, Mano S (2006) Measurement of air pollution in indoor artificial turf halls Norwegian Institute for Air Pollution

European Chemicals Agency (2017) An evaluation of the possible health risks of recycled rubber granules used as infill in synthetic turf sports fields

Fernandez LA, Lao W, Maruya KA, Burgess RM (2014) Calculating the diffusive flux of persistent organic pollutants between sediments and the water column on the Palos Verdes shelf superfund site using polymeric passive samplers. Environ Sci Technol 48:3925-3934. https://doi.org/10.1021/es404475c

Ginsberg G, Toal B, Simcox N, Bracker A, Golembiewski B, Kurland T, Hedman C (2011) Human health risk assessment of synthetic turf fields based upon investigation of five fields in Connecticut. J Toxicol Environ Health A 74:1150-1174. https://doi.org/10.1080/ 15287394.2011 .586942

Han J, Won E-J, Hwang D-S, Shin KH, Lee YS, Leung KMY, Lee SJ, Lee JS (2014) Crude oil exposure results in oxidative stressmediated dysfunctional development and reproduction in the copepod Tigriopus japonicus and modulates expression of cytochrome P450 (CYP) genes. Aquat Toxicol 152:308-317. https://doi.org/10. 1016/j.aquatox.2014.04.027

Hou R, Xu Y, Wang Z (2016) Review of OPFRs in animals and humans: absorption, bioaccumulation, metabolism, and internal exposure research. Chemosphere 153:78-90. https://doi.org/10.1016/j. chemosphere.2016.03.003

Huckins JN, Petty JD, Lebo JA, Almeida FV, Booij K, Alvarez DA, Cranor WL, Clark RC, Mogensen BB (2002) Development of the permeability/performance reference compound approach for in situ calibration of semipermeable membrane devices. Environ Sci Technol 36:85-91. https://doi.org/10.1021/es010991w

Kanematsu M, Hayashi A, Denison MS, Young TM (2009) Characterization and potential environmental risks of leachate from shredded rubber mulches. Chemosphere 76:952-958. https://doi. org/10.1016/j.chemosphere.2009.04.026

Khairy M, Lohmann R (2014) Field calibration of low-density polyethylene passive samplers for gaseous POPs. Environ Sci Processes Impacts 16:414-421. https://doi.org/10.1039/C3EM00493G

Knecht AL, Goodale BC, Truong L, Simonich MT, Swanson AJ, Matzke MM, Anderson KA, Waters KM, Tanguay RL (2013) Comparative developmental toxicity of environmentally relevant oxygenated PAHs. Toxicol Appl Pharmacol 271:266-275

Lapczynski A, McGinty D, Jones L, Bhatia S, Letizia CS, Api AM (2007) Fragrance material review on benzyl salicylate. Food Chem Toxicol 45(Suppl 1):S362-S380. https://doi.org/10.1016/j.fct.2007.09.036

Li X, Berger W, Musante C, Mattina MI (2010) Characterization of substances released from crumb rubber material used on artificial turf fields. Chemosphere 80:279-285. https://doi.org/10.1016/j. chemosphere.2010.04.021

Llompart M, Sanchez-Prado L, Pablo Lamas J, Garcia-Jares C, Roca E, Dagnac T (2013) Hazardous organic chemicals in rubber recycled tire playgrounds and pavers. Chemosphere 90:423-431. https://doi. org/10.1016/j.chemosphere.2012.07.053

Lundstedt S, White PA, Lemieux CL, Lynes KD, Lambert IB, Öberg L, Haglund P, Tysklind M (2007) Sources, fate, and toxic hazards of oxygenated polycyclic aromatic hydrocarbons (PAHs) at PAH- contaminated sites. AMBIO J Hum Environ 36:475-485. https:// doi.org/10.1579/0044-7447(2007)36[475:sfatho]2.0.co;2

Lygre H, Hol PJ, Solheim E, Moe G (1999) Organic leachables from polymer-based dental filling materials. Eur J Oral Sci 107:378-383

Nilsson NH, Malmgren-Hansen B, Thomsen US (2008) Mapping, emissions and environmental and health assessment of chemical substances in artificial turf. Danish Ministry of the Environment

O'Connell SG, Haigh T, Wilson G, Anderson KA (2013) An analytical investigation of 24 oxygenated-PAHs (OPAHs) using liquid and gas chromatography-mass spectrometry. Anal Bioanal Chem 405: 8885-8896. https://doi.org/10.1007/s00216-013-7319-x

O'Connell SG, Kincl LD, Anderson KA (2014) Silicone wristbands as personal passive samplers. Environ Sci Technol 48:3327-3335. https://doi.org/10.1021/es405022f

O'Connell SG, McCartney MA, Paulik LB, Allan SE, Tidwell LG, Wilson G, Anderson KA (2014) Improvements in pollutant monitoring: optimizing silicone for co-deployment with polyethylene passive sampling devices. Environ Pollut 193:71-78. https://doi. org/10.1016/j.envpol.2014.06.019

Ramírez N, Cuadras A, Rovira E, Marcé RM, Borrull F (2011) Risk assessment related to atmospheric polycyclic aromatic hydrocarbons in gas and particle phases near industrial sites. Environ Health Perspect 119:1110-1116

Ribeiro-Filho HV, de Souza Silva CM, de Siqueira RJ, Lahlou S, dos Santos AA, Magalhaes PJ (2016) Biphasic cardiovascular and respiratory effects induced by beta-citronellol. Eur J Pharmacol 775: 96-105. https://doi.org/10.1016/j.ejphar.2016.02.025

Sadiktsis I, Bergvall C, Johansson C, Westerholm R (2012) Automobile tires-a potential source of highly carcinogenic dibenzopyrenes to the environment. Environ Sci Technol 46:3326-3334. https://doi.org/ $10.1021 /$ es204257d

Samburova V, Zielinska B, Khlystov A (2017) Do 16 polycyclic aromatic hydrocarbons represent PAH air toxicity? Toxics 5:17

Schiliro T, Traversi D, Degan R et al (2013) Artificial turf football fields: environmental and mutagenicity assessment. Arch Environ Contam Toxicol 64:1-11. https://doi.org/10.1007/s00244-012-9792-1

Shen G, Zhang Y, Wei S, Chen Y, Yang C, Lin P, Xie H, Xue M, Wang X, Tao S (2014) Indoor/outdoor pollution level and personal inhalation exposure of polycyclic aromatic hydrocarbons through biomass 
fuelled cooking. Air Qual Atmos Health 7:449-458. https://doi.org/ 10.1007/s11869-014-0262-y

Smedes F, Geertsma RW, Zande T, Booij K (2009) Polymer-water partition coefficients of hydrophobic compounds for passive sampling: application of Cosolvent models for validation. Environ Sci Technol 43:7047-7054. https://doi.org/10.1021/es9009376

Thang PQ, Taniguchi T, Nabeshima Y, Bandow H, Trung NQ, Takenaka N (2014) Distribution of polycyclic aromatic hydrocarbons concentrations simultaneously obtained in gas, rainwater and particles. Air Qual Atmos Health 7:273-281. https://doi.org/10.1007/s11869013-0234-7

USEPA (2010) Development of a relative potency factor approach for PAH mixtures

USEPA (2016) Federal Research Action Plan on Recycled Tire Crumb Used on Playing Fields and Playgrounds STATUS REPORT

Wincent E, Le Bihanic F, Dreij K (2016) Induction and inhibition of human cytochrome $\mathrm{P} 4501$ by oxygenated polycyclic aromatic hydrocarbons. Toxicol Res 5:788-799. https://doi.org/10.1039/ c6tx00004e
World Health Organization (2009) The WHO Recommended Classification of Pesticides by Hazard

Xu Y, Zhang J (2011) Understanding SVOCs. ASHRAE J 53:121-125

Yagishita M, Kageyama S, Ohshima S, Matsumoto M, Aoki Y, Goto S, Nakajima D (2015) Atmospheric concentration and carcinogenic risk of polycyclic aromatic hydrocarbons including benzo[c]fluorene, cyclopenta[c,d]pyrene, and benzo[j]fluoranthene in Japan. Atmos Environ 115:263-268. https://doi.org/10.1016/j. atmosenv.2015.05.050

Zhang JJ, Han IK, Zhang L, Crain W (2008) Hazardous chemicals in synthetic turf materials and their bioaccessibility in digestive fluids. J Expo Sci Environ Epidemiol 18:600-607. https://doi.org/10.1038/ jes. 2008.55 